\title{
Monitoring vegetation phenology using an infrared-enabled security camera
}

\section{Citation}

Petach, Anika R., Michael Toomey, Donald M. Aubrecht, and Andrew D. Richardson. 2014.

"Monitoring Vegetation Phenology Using an Infrared-Enabled Security Camera." Agricultural and Forest Meteorology 195-196 (September): 143-151.

\section{Published Version}

doi:10.1016/j.agrformet.2014.05.008

\section{Permanent link}

http://nrs.harvard.edu/urn-3:HUL.InstRepos:12748552

\section{Terms of Use}

This article was downloaded from Harvard University's DASH repository, and is made available under the terms and conditions applicable to Open Access Policy Articles, as set forth at http:// nrs.harvard.edu/urn-3:HUL.InstRepos:dash.current.terms-of-use\#OAP

\section{Share Your Story}

The Harvard community has made this article openly available.

Please share how this access benefits you. Submit a story.

Accessibility 
Monitoring vegetation phenology using an infrared-enabled security camera

Anika R. Petach ${ }^{1}$, Michael Toomey ${ }^{2}$, Donald M. Aubrecht ${ }^{2}$, and Andrew D. Richardson ${ }^{2, *}$

${ }^{1}$ Harvard University, Department of Earth and Planetary Sciences and School of Engineering and Applied Sciences

${ }^{2}$ Harvard University, Department of Organismic and Evolutionary Biology

*HUH, 22 Divinity Avenue, Cambridge, MA 02138; arichardson@oeb.harvard.edu. 


\section{Abstract}

2 Sensor-based monitoring of vegetation phenology is being widely used to quantify

3 phenological responses to climate variability and change. Digital repeat photography, in

4 particular, can characterize the seasonality of canopy greenness. However, these data cannot be

5 directly compared to satellite vegetation indices (e.g., NDVI, the normalized difference

6 vegetation index) that require information about vegetation properties at near-infrared (NIR)

7 wavelengths. Here, we develop a new method, using an inexpensive, NIR-enabled camera

8 originally designed for security monitoring, to calculate a "camera NDVI" from sequential

9 visible and visible+NIR photographs. We use a lab experiment for proof-of-concept, and then

10 test the method using a year of data from an ongoing field campaign in a mixed temperate forest.

11 Our analysis shows that the seasonal cycle of camera NDVI is almost identical to that of NDVI

12 measured using narrow-band radiometric instruments, or as observed from space by the MODIS

13 platform. This camera NDVI thus provides different information about the state of the canopy

14 than can be obtained using only visible-wavelength imagery. In addition to phenological

15 monitoring, our method should be useful for a variety of applications, including continuous

16 monitoring of plant stress and quantifying vegetation responses to manipulative treatments in

17 large field experiments.

20 Keywords: Digital repeat photography; green chromatic coordinate $\left(\mathrm{g}_{\mathrm{CC}}\right)$; near-surface remote

21 sensing; normalized difference vegetation index (NDVI); phenology; stress monitoring. 


\section{Introduction}

The phenology of terrestrial vegetation is highly sensitive to climate variability and change (Rosenzweig et al., 2007; Migliavacca et al., 2012). In the context of climate change,

4 phenology is important because it mediates many of the feedbacks between terrestrial vegetation 5 and the climate system (Richardson et al., 2013a). From an ecological perspective, phenology

6 plays an important role in both competitive interactions and trophic dynamics, as well as in 7 reproductive biology, primary production, and nutrient cycling (Morisette et al., 2009).

8 Satellite remote sensing can provide global coverage of vegetation phenology, but suffers 9 from tradeoffs between spatial and temporal resolution (Zhang et al., 2003; White et al., 2009).

10 Thus, over the last decade, there has been great enthusiasm for increased on-the-ground

11 monitoring of phenology (Betancourt et al., 2005; Morisette et al., 2009; Polgar and Primack,

12 2011). The general objective of these efforts is to better understand spatial and temporal

13 variation in phenology, and how this variability is driven by environmental factors such as

14 temperature, precipitation, and photoperiod (or insolation). Citizen science networks, such as the

15 USA National Phenology Network (http://www.usanpn.org) and Project Budburst

16 (http://budburst.org), are playing an important role in this monitoring, by engaging large

17 numbers of motivated volunteers and establishing standardized protocols.

18 Instrument-based approaches (Richardson et al., 2013b) provide a compelling alternative

19 to observer-based phenology, because of the potential for high frequency, automated data

20 collection in a manner that is scalable for regional or continental monitoring. In this context,

21 digital repeat photography (e.g. Richardson et al., 2007, 2009; Sonnentag et al., 2012) is an

22 attractive option because images can be analyzed either qualitatively or quantitatively, and

23 analysis can focus on individual organisms or integrate across the field of view to obtain a

24 community- or canopy-level perspective. Compared to data collected by a human observer,

25 which tend to focus on discrete phenophases, such as flowering or budburst, the entire seasonal

26 trajectory of canopy greenness can be characterized from digital camera imagery. Additionally,

27 the archived images provide a permanent visual record that can be reanalyzed as new tools and

28 questions are developed. Camera-based monitoring (e.g. the PhenoCam network,

29 http://phenocam.sr.unh.edu/) thus provides data at a spatial scale that is intermediate between

30 ground observations of individual plants and satellite remote sensing. 
To date, most camera-based monitoring of vegetation phenology has been conducted using standard, consumer-grade digital cameras (e.g. Sonnentag et al., 2012). These typically record a three-layer image (red, green and blue: RGB), which is sufficient for the representation

4 of colors in the visible spectrum (VIS, $\lambda=400-700 \mathrm{~nm}$ ) as perceived by the human eye. For 5 quantitative analysis, the average value of each color layer for all pixels within a user-defined region of interest (ROI) is extracted from each image to yield a digital number triplet ( $R_{\mathrm{DN}}, G_{\mathrm{DN}}$,

$\begin{array}{ll}7 & \left.B_{\mathrm{DN}}\right) \text {. Then seasonal variation in the state of the canopy is characterized by the use of several }\end{array}$ 8 color indices, such as the green chromatic coordinate $\left(g_{\mathrm{CC}}\right.$, Eq. 1a) and excess green $\left(G_{\mathrm{ex}}\right.$, Eq. 1b) (Sonnentag et al., 2012; Richardson et al., 2013b):

$$
\begin{array}{ll}
g_{\mathrm{CC}}=G_{\mathrm{DN}} /\left(R_{D N}+G_{D N}+B_{D N}\right) & \text { Eq. 1a } \\
G_{\mathrm{EX}}=2 G_{\mathrm{DN}}-\left(R_{\mathrm{DN}}+B_{\mathrm{DN}}\right) & \text { Eq. 1b }
\end{array}
$$

Conversely, satellite remote sensing of vegetation has traditionally used both visible and near-infrared (NIR, $\lambda=700-1400 \mathrm{~nm}$ ) wavelengths. The reason for this is that healthy vegetation can be distinguished from other land cover types by its unique spectral signature, which combines low reflectance in the VIS with high reflectance in the NIR. Thus, the camera indices presented above, which are based only VIS wavelengths, are not directly comparable to standard satellite vegetation indices such as NDVI (Normalized Difference Vegetation Index, Eq. 1c), calculated from red band and NIR band reflectances ( $\rho_{\mathrm{R}}$ and $\rho_{\mathrm{NIR}}$, respectively) (Tucker, 1979).

$$
N D V I=\left(\rho_{\mathrm{R}}-\rho_{\mathrm{NIR}}\right) /\left(\rho_{R}+\rho_{\mathrm{NIR}}\right) \quad \text { Eq. } 1 \mathrm{c}
$$

Intriguingly, the $\mathrm{CCD}$ (charge-coupled device) or CMOS (complementary metal-oxidesemiconductor) imaging sensors used in most digital cameras are sensitive to wavelengths in the NIR portion of the spectrum. An infrared cut filter is typically used to block these wavelengths from reaching the imaging sensor, as they are beyond the spectral range to which the human eye is sensitive and are thus not necessary for conventional color photography. Customized cameras have been used in the past to leverage this NIR sensitivity (Shibayama et al., 2009, 2011; Sakamoto et al., 2010, 2012; Nijland et al., 2013). For example, using a two-camera system Sakamoto et al. (2012) calculated an NDVI-style index that was more akin to the conventional NDVI than either $g_{\mathrm{CC}}$ or $G_{\mathrm{EX}}$. The two-camera approach allows for simultaneous recording of information about the VIS and NIR properties of vegetation, but creates challenges related to camera alignment, cross-calibration, and synchronization of image capture. Very recently,

31 relatively low-cost NDVI cameras have become available (e.g. MaxMax, Event-38, and Regent 
1 brands), but these have not been produced with long-term monitoring in mind, and such cameras

2 are unable to also produce conventional RGB imagery - that is, infrared wavelengths are

3 recorded at the expense of information in one of the RGB channels.

$4 \quad$ Here, we show that a commercially-available, network-enabled camera ("webcam") with

5 a software-controlled infrared cut filter overcomes the above limitations. With the cut filter in

6 place, standard 3-layer RGB imagery is recorded; with the filter removed, a monochrome

7 RGB+NIR image is obtained. We develop a method to compute an NDVI-style vegetation index,

8 which we call "camera NDVI", from this imagery. A lab experiment, conducted under controlled

9 conditions, is used as a proof-of-concept. We then apply the method to a one-year archive of

10 images from the Harvard Forest to demonstrate the feasibility of employ this method for field

11 monitoring of vegetation phenology, where day-to-day variation in weather and lighting cause

12 additional challenges. As a final test, we compare the seasonality of camera NDVI from the

13 Harvard Forest data with that obtained using co-located narrow-band radiometric instruments

14 and from satellite sensors. Data from our camera system will be of value for quality assessment

15 of phenology products derived from satellite imagery (e.g. White et al., 2009).

\section{Material and Methods}

\section{Camera}

19 We used a NetCam SC IR (StarDot Technologies, Buena Park, CA) camera, featuring a

20 Micron $1 / 2$ " CMOS active-pixel digital imaging sensor and configured for 1.3 megapixel (1296 x

21 976) output. The camera was set at manual (fixed) white balance and, unless otherwise noted,

22 automatic exposure. With a built-in uClinux operating system, the camera operates as a

23 standalone system with Internet connectivity. Command scripts running on the camera controlled

24 the infrared cut filter, image capture, and image upload to a remote server via FTP. The

25 customized scripts used here are available in the "Tools" section of the PhenoCam project page

26 (http://phenocam.sr.unh.edu/webcam/tools/) or from the corresponding author.

Proof-of-concept lab experiment

29 We conducted a lab experiment to evaluate whether camera imagery can be used to 30 accurately characterize the broadband spectral properties of different materials. We used the

31 StarDot camera to record sequential color RGB and monochrome RGB+NIR images of materials 
1 with a wide range of spectral signatures (Figure 1). Each sample was illuminated from above

2 with a $50 \mathrm{~W}$ Halogen lamp designed for indoor diffuse reflectance measurements (ASD

3 ProLamp, Analytical Spectral Devices Inc., Boulder, CO). The StarDot camera was mounted on

4 a tripod to the side of the sample and inclined downward at an angle of about $45^{\circ}$. Each sample

5 filled approximately one-quarter of the camera's field of view. For quality assurance, we

6 included a multi-color reference panel in each image, made by painting red, green, blue, white

7 and grey strips on a flat piece of plastic. We recorded four images of each sample: one image at

8 fixed exposure (1/300 s) for both color RGB and monochrome RGB+NIR images, and one

9 image at automatic exposure for both color RGB and monochrome RGB+NIR. Automatic

10 exposure values were determined by the camera. The mean automatic exposure for the color

11 RGB images was $1 / 30 \mathrm{~s}$ (minimum 1/120 s), compared with $1 / 200 \mathrm{~s}$ (minimum 1/350 s) for the

12 monochrome RGB+NIR images. Thus the fixed exposure images were almost always under-

13 exposed compared to the automatic exposure images.

14 We measured the reflectance spectrum $(\lambda=350-2500 \mathrm{~nm})$ of each sample using a

15 spectroradiometer (ASD FieldSpec 3, Analytical Spectral Devices Inc.) connected to a $5 \mathrm{~cm}$ (2

16 inch) three-port integrating sphere (SphereOptics, Concord, NH) and a $10 \mathrm{~W}$ hemispheric

17 collimated light source with a $6 \mathrm{~V}$ regulated power supply. White Spectralon discs were used as

18 reference standards. The sphere featured an $8^{\circ}$ near-normal incidence port, such that reflectance

19 measurements include both diffuse and specular components. We processed the raw data to

20 reflectances (1 $\mathrm{nm}$ increment) using ViewSpecPro software (Analytical Spectral Devices Inc.).

21 Spectroradiometer NDVI was calculated using red and NIR band reflectances; specific

22 wavelength ranges are reported below.

23 Most of the samples (42) for this experiment were leaves picked from a selection of trees

24 and shrubs native to New England, representing a wide range of leaf health and corresponding

25 colors, from fresh dark green to senesced red to fallen brown leaves (Figure 1). We included

26 other materials, including asphalt, cardboard, wood, and several paint color chips, for a total of

2751 samples.

29 Field data

30 We used field data from an ongoing measurement campaign at the $40 \mathrm{~m}$ "Barn Tower"

$31\left(42.5353^{\circ} \mathrm{N} 72.1899^{\circ} \mathrm{W}\right)$ at the Harvard Forest, near the town of Petersham, MA, $110 \mathrm{~km}$ west of 
1 Boston. Mixed forest stands surrounding the tower are dominated by the deciduous species red

2 oak (Quercus rubra L., $40 \%$ of basal area) and red maple (Acer rubrum L., $\sim 20 \%$ of basal

3 area), with evergreen white pine (Pinus strobus L.) the dominant conifer. The MODIS land cover

4 classification for the tower, and the land immediately surrounding the tower, is deciduous

5 broadleaf forest.

We used imagery (April 1, 2012 through March 30, 2013) from a StarDot camera that is mounted at the top of the tower. The camera points north and is inclined $\sim 30^{\circ}$ below horizontal.

8 As in the lab experiments, command scripts on the camera trigger the infrared cut filter and 9 obtain successive (about $30 \mathrm{~s}$ apart) color RGB and monochrome RGB+NIR imagery. Automatic

10 exposure is used for each image. Images are uploaded by FTP to a remote server every 15

11 minutes between 4 a.m. and 10 p.m.

12 Also mounted atop the same tower is a pair of 4-channel (blue: $470 \pm 20 \mathrm{~nm}$, green: 557

$13 \pm 25 \mathrm{~nm}$, red: $605 \pm 35 \mathrm{~nm}$, NIR: $750 \pm 42 \mathrm{~nm}$ ) narrowband radiometric sensors (Model 1850,

14 Skye Instruments, Llandrindod Wells, UK). One unit with a cosine diffuser is pointed upwards to 15 measure incident solar radiation, while the second unit, with a $25^{\circ}$ field of view, is pointed in the 16 same direction as the StarDot camera to measure radiation reflected by the canopy. We log

17 measurements every 15 seconds and record 30 minute averages on a datalogger (CR1000,

18 Campbell Scientific, Logan, UT). From these data, we calculated canopy reflectance $\left(\rho_{i}\right)$ as in

19 Eq. 2, where $Q_{\mathrm{i}} \downarrow$ and $Q_{\mathrm{i}} \uparrow$ are measurements of the incident and reflected quantum flux,

20 respectively, for each band $i$, and the calibration constant $\left(k_{\mathrm{i}}\right)$ determined under natural (sunlit)

21 conditions using a Spectralon panel.

$$
\rho_{\mathrm{i}}=k_{i}\left(Q_{\mathrm{i}}^{\uparrow} / Q_{\mathrm{i}}^{\downarrow}\right)
$$

Eq. 2

We calculated two indices from the narrowband radiometric sensors: radiometer NDVI

24 (Eq. 3a) and radiometer $g_{\mathrm{CC}}$ (Eq. 3b):

$$
\begin{aligned}
& \text { radiometer NDVI }=\left(\rho_{750}-\rho_{605}\right) /\left(\rho_{750}+\rho_{605}\right) \\
& \text { radiometer } g_{\mathrm{CC}}=\rho_{557} /\left(\rho_{605}+\rho_{557}+\rho_{470}\right)
\end{aligned}
$$

Eq. $3 \mathrm{a}$

Eq. $3 b$

Image processing

Briefly, image analysis for both lab and field data included manual delineation of an appropriate ROI and extraction of color channel information for that ROI in each image. We also 
used an optical character recognition algorithm to read the image exposure from the text overlay

2 at the top of each image.

For the lab experiment, the ROI was adjusted for each sample to include as much of the

4 sample as possible. For the field data, we defined separate deciduous (predominantly red oak and 5 red maple) and conifer (white pine) ROIs, which were each roughly $440 \times 440$ pixels in size. The camera field of view did not change over time, and thus these ROIs were fixed over the period of 7 analysis.

8 We processed the camera imagery as follows. For each sample, we defined the ROI and 9 determined the average pixel value (digital number) across the ROI for three channels in the 10 color RGB images $\left(R_{\mathrm{DN}}, G_{\mathrm{DN}}, B_{\mathrm{DN}}\right)$ and one channel in the monochromatic RGB+IR images

$11\left(Z_{\mathrm{DN}}\right)$. If both images were taken at the same exposure, then the monochrome RGB+IR images

12 could be partitioned to a visible component $\left(Y_{\mathrm{DN}}\right)$ plus a NIR component $\left(X_{\mathrm{DN}}\right)$ according to Eq.

13 4a, with the visible component calculated from the color RGB images as in Eq. 4b (Daniel

14 Lawton, StarDot Technologies, personal communication). Then the NIR component, $X_{\mathrm{DN}}$, was 15 estimated as $Z_{\mathrm{DN}}-Y_{\mathrm{DN}}$.

Eq. $4 \mathrm{a}$

Eq. $4 b$

However, if the images were taken at different exposures (where $E_{\mathrm{Y}}$ denotes the exposure of the color RGB image and $E_{\mathrm{Z}}$ the exposure of the RGB+IR image), then these exposure differences had to be accounted for. Exploratory analyses indicated that division through by the square root of the exposure time offered a straightforward solution (Eq. 5a-d) to exposure adjustment. Note that camera systems with different gamma values, where $\gamma$ is the exponent in the power law relationship between input and output signals of digital imaging systems, may be different (cf. Sakamoto et al., 2010, 2012). Taking the square root of $E$ assumes a $\gamma=2.0$, a reasonable approximation of the actual StarDot value of $\gamma=1.7$ (Daniel Lawton, StarDot Technologies, personal communication). However, our results were essentially the same regardless of whether we used 2.0 or 1.7 .

$$
\begin{array}{ll}
Z_{\mathrm{DN}}^{\prime}=Z_{\mathrm{DN}} / \sqrt{E_{\mathrm{Z}}} & \text { Eq. } 5 \mathrm{a} \\
R_{\mathrm{DN}}^{\prime}=R_{\mathrm{DN}} / \sqrt{E_{\mathrm{Y}}} & \text { Eq. } 5 \mathrm{~b} \\
Y_{\mathrm{DN}}^{\prime}=Y_{\mathrm{DN}} / \sqrt{E_{\mathrm{Y}}} & \text { Eq. } 5 \mathrm{c}
\end{array}
$$




$$
X_{\mathrm{DN}}^{\prime}=Z_{\mathrm{DN}}^{\prime}-Y_{\mathrm{DN}}^{\prime}
$$

Eq. $5 d$

We calculated camera NDVI as in Eq. 6, in terms of exposure-adjusted digital numbers.

3 For fixed-exposure images, the same calculation was used, ignoring the primes (').

$$
\text { Camera NDVI }=\left(X_{\mathrm{DN}}^{\prime}-R_{\mathrm{DN}}^{\prime}\right) /\left(X_{\mathrm{DN}}^{\prime}+R_{\mathrm{DN}}^{\prime}\right) \quad \text { Eq. } 6
$$

For both radiometer and camera data, there was substantial variability in the derived

6 indices at the 30 minute time step, which may be associated with factors such as overall light

7 levels, cloudiness, and illumination geometry (see further analysis in Results). After comparing

8 various averaging, quantile, and filtering methods, we derived daily estimates by calculating the

9 arithmetic mean across all observations where the incident photosynthetic photon flux density

10 (PPFD; measured at the top of the tower using a PQS-1 quantum sensor, Kipp \& Zonen, Delft,

11 the Netherlands) was greater than $200 \mu \mathrm{mol} \mathrm{m}^{-2} \mathrm{~s}^{-1}$. This method reduced day-to-day variability

12 in the resulting time series better than the $90^{\text {th }}$ percentile approach used by Sonnentag et al.

13 (2012), although an obvious advantage of the latter approach is that it does not require solar

14 radiation data.

15 Because $R_{\mathrm{DN}}^{\prime}$ and $X_{\mathrm{DN}}^{\prime}$ are not direct measurements of reflectance, the magnitude of 16 camera NDVI depends on the spectral distribution of the incident light. Thus, camera NDVI

17 values from the lab experiments are not directly comparable to those from the field experiment,

18 and those from the field experiment are not comparable to either radiometer or satellite NDVI

19 values. To compensate for this, we re-scaled camera NDVI (yielding camera NDVI ${ }^{\mathrm{R}}$ ) by

20 estimating the coefficients of a linear regression between camera NDVI (for the deciduous ROI)

21 and radiometer NDVI, where $a$ is a slope coefficient, $b$ is the $y$-axis intercept and $\varepsilon$ is the model

22 residual:

$$
\text { radiometer NDVI }=a(\text { camera NDVI })+b+\varepsilon
$$

Eq. 7

\section{Results}

\section{Lab experiment}

$27 \quad$ Spectral reflectance signatures differ markedly among the 51 samples scanned by the 28 spectroradiometer (Figure 1). There are pronounced differences in reflectance spectra between 29 green, yellowing, and red leaves, but the non-foliar samples added greatly to the variability 30 among samples across both visible and near-infrared wavelengths. The variation in reflectance 
1 across samples is smallest for violet and blue (400-500 nm) wavelengths, and largest for red

2 (620-700 $\mathrm{nm})$ and near infrared (700-1000 nm) wavelengths.

$3 \quad$ For the fixed exposure imagery (results not illustrated), digital numbers extracted from

4 camera imagery for the red channel $\left(R_{\mathrm{DN}}\right)$ are well correlated with mean reflectance over red

5 wavelengths $(620-700 \mathrm{~nm})$ measured with the spectroradiometer $(r=0.91)$. Similarly, digital

6 numbers for the near infrared $\left(X_{\mathrm{DN}}\right)$ component of the RGB+NIR imagery are well correlated

7 with mean reflectance over NIR wavelengths $(700-1000 \mathrm{~nm})$ measured with the

8 spectroradiometer $(r=0.87)$. Camera NDVI is well correlated with spectroradiometer NDVI

9 using these broad bands ( $r=0.91$ ), or using the spectral range of MODIS bands (band $1=620$

$10670 \mathrm{~nm}$, band $2=841-867 \mathrm{~nm})(r=0.93)$.

11 We used an iterative procedure to identify the wavelengths across which reflectance

12 measured by the spectroradiometer is most highly correlated with $R_{\mathrm{DN}}$ and $X_{\mathrm{DN}}$ from the fixed

13 exposure imagery. For $R_{\mathrm{DN}}$, we obtained a correlation of $r=0.96$ across the range from 570-660

$14 \mathrm{~nm}$ (Figure 2A), whereas for $X_{\mathrm{DN}}$, we find a correlation of $r=0.91$ across the range from 805-

$15815 \mathrm{~nm}$ (Figure 2B). For the fixed exposure imagery, there is an excellent correlation $(r=0.99)$

16 between camera NDVI and spectroradiometer NDVI calculated using these particular bands

17 (Figure 2C).

18 We conducted a similar analysis for the automatic exposure imagery. Exposure-adjusted

19 digital numbers (Eq. 5b, 5d) for each channel are best correlated with mean reflectance,

20 measured by the spectroradiometer, across an appropriate range of wavelengths (Figure 3). For

21 example, $B_{\mathrm{DN}}^{\prime}$ is most strongly correlated with mean reflectance across violet and blue

22 wavelengths (430-515 nm, $r=0.92), G_{\mathrm{DN}}^{\prime}$ with green wavelengths (510-570 nm, $\left.r=0.94\right), R_{\mathrm{DN}}^{\prime}$

23 with yellow and red wavelength (575-710 nm, $r=0.96$; Figure 4A), and $X_{\mathrm{DN}}^{\prime}$ with near infrared

24 wavelengths ( $800-815 \mathrm{~nm}, r=0.88$; Figure 4B). The contour plots in Figure 3 show how the

25 strength of these correlations tended to fall off rapidly outside the optimal range. For example,

$26 R_{\mathrm{DN}}^{\prime}$ is not well correlated with wavelengths $<575 \mathrm{~nm}$ or $>710 \mathrm{~nm}$, and $X_{\mathrm{DN}}^{\prime}$ is not well

27 correlated with wavelengths $<700 \mathrm{~nm}$. For the automatic exposure imagery, camera NDVI is

28 very well correlated with spectroradiometer NDVI using either the most-highly-correlated bands

29 identified here (i.e. red 575-710 nm and NIR 800-815 nm; $r=0.96$, Figure 4C), or the standard

30 MODIS bands $(r=0.94)$. 
Results from the lab experiment demonstrate the potential of the StarDot camera imagery

2 for characterizing the spectral properties of diverse materials, particularly in red and near

3 infrared bands. By processing sequential VIS and VIS+NIR images, we are able to back-

4 calculate the NIR component. Furthermore, this experiment shows that camera NDVI is strongly

5 correlated with spectroradiometer NDVI when using either fixed exposure or automatic exposure

6 imagery. Since field images are recorded with automatic exposures to optimize dynamic range

7 under varying illumination conditions, our ability to correct for variations in exposure is critical.

8 These lab results prove that camera NDVI is sensitive to the variation in reflectances of a wide

9 range of materials and surfaces. This indicates the potential for monitoring canopy phenology in

10 the field using a similar approach to characterize the seasonal variation in canopy optical

11 properties, as described in the following section.

\section{Field measurements}

14 The green chromatic coordinate calculated from the narrowband radiometric sensors,

15 radiometer $g_{\mathrm{CC}}$ (Figure 5A), exhibits a seasonal pattern that is typical of deciduous forests (e.g.,

16 Sonnentag et al., 2012; Richardson et al., 2013b). Radiometer $g_{\mathrm{CC}}$ rises rapidly in spring with

17 budburst (day 115-120) and leaf development to a pronounced spiky peak (day 140; see Keenan

18 et al., 2014, for discussion), before decreasing gradually over the course of the summer, and then

19 declining rapidly (day 250) in autumn with leaf coloration and abscission (day 300). For the

20 deciduous ROI, camera $g_{\mathrm{CC}}$ (Figure 5B) follows essentially the same seasonal pattern, with the

21 notable exception of a more pronounced dip in greenness around day 290, corresponding to the

22 peak of autumn colors and a marked increase in canopy redness that is clearly visible in the RGB

23 camera imagery. The coniferous ROI shows a seasonally varying signal in camera $g_{\mathrm{CC}}$ (Figure

24 5C), but with substantially smaller amplitude than that for the deciduous ROI, reflecting the

25 year-round presence of foliage but nevertheless indicating seasonal variation in foliar chlorophyll

26 concentrations (Richardson et al., 2009). The start of spring green-up also begins about 30 days

27 earlier, and the end of the autumn decline ends about 60 days later, for the coniferous ROI

28 compared to the deciduous ROI.

29 By contrast, the seasonal cycle of radiometer NDVI differs from that of radiometer (or

30 camera) $g_{\mathrm{CC}}$ (Figure 5D). The primary difference is the absence of the spike seen in $\mathrm{g}_{\mathrm{CC}}$ around

31 day 140. A secondary difference is the presence of a broad plateau in radiometer NDVI from 
1 about day 130 to day 240. As a result, radiometer NDVI gives a better representation of the

2 seasonal dynamics of canopy leaf area index (LAI) than does radiometer $g_{\mathrm{CC}}$ (e.g. compare with

3 Fig. 1 in Richardson et al., 2012). Additionally, the seasonal cycle of radiometer NDVI roughly

4 parallels (and is comparable in magnitude to) that of MODIS NDVI (Figure 5D). In particular,

5 the timing of the spring increase and autumn decrease in NDVI is similar in both time series.

6 However, during the winter months the MODIS data are somewhat noisier than the radiometer 7 data.

8 There is a strong linear relationship $\left(R^{2}=0.89\right)$ between radiometer NDVI and camera

9 NDVI for the deciduous ROI. The best-fit linear scaling coefficients (Eq. 7) are $a=0.53 \pm 0.02$

10 SE and $b=0.84 \pm 0.01$, with $\sigma(\varepsilon)=0.041$. Henceforth, we focus on the rescaled time series,

11 camera $\mathrm{NDVI}^{\mathrm{R}}$, for which the seasonal cycle is much more similar in shape to that of radiometer

12 NDVI than camera $g_{\mathrm{CC}}$. For example, the relative rate of increase in both radiometer NDVI and

13 camera $\mathrm{NDVI}^{\mathrm{R}}$ for the deciduous region of interest in spring is more gradual than the

14 corresponding rate of increase in radiometer or camera $g_{\mathrm{CC}}$, and conspicuously absent in the 15 camera $\mathrm{NDVI}^{\mathrm{R}}$ data for the deciduous region of interest is the $\mathrm{g}_{\mathrm{CC}}$ spike that occurs around day

16 140. For the coniferous region of interest, camera $g_{\mathrm{CC}}$ shows a seasonal pattern that is less

17 pronounced than that for the deciduous region of interest. However, there is no clear seasonal

18 cycle in the camera NDVI ${ }^{\mathrm{R}}$ data for the coniferous region of interest. Together, these results

19 suggest that camera NDVI is capturing different aspects of seasonal canopy dynamics than

20 indices, such as $g_{\mathrm{CC}}$, that are based only on visible wavelengths (cf. Nijland et al. 2013). The use

21 of both $g_{\mathrm{CC}}$ and camera NDVI together give more information than can be obtained from either

22 index on its own. The advantage of $g_{\mathrm{CC}}$ is that it is sensitive to leaf color, which is related to

23 pigmentation (Keenan et al. 2014), while camera NDVI is a better proxy for LAI.

Non-phenological sources of variability in camera NDVI

Even with averaging of 30-minute data to a daily product, the signal-to-noise ratio of

27 camera $\mathrm{NDVI}^{\mathrm{R}}$ is somewhat higher than that of camera $g_{\mathrm{CC}}$ (day-to-day variability being equal to

28 about $8 \%$ of the seasonal amplitude for camera $\mathrm{NDVI}^{\mathrm{R}}$, compared with $5 \%$ for camera $g_{\mathrm{CC}}$;

29 compare Figures 5B and 5E), and indeed also higher than that of radiometer NDVI (compare

30 figures 5E and 5D). Of course, some of the variation in both camera NDVI and radiometer NDVI

31 can potentially be attributed to sky condition, shadow fraction, and illumination geometry, all of 
1 which can change over the course of the day or between one day and the next. And, some of this

2 variability is undoubtedly the result of the brief (30 s) lag between the VIS and VIS+NIR

3 imagery, which is unavoidable as the camera needs some time to adjust after the cut filter has

4 been triggered on or off.

5 We further investigate some of the factors associated with variability in camera NDVI

6 using the 30-minute data, focusing on the period from day 160 to day 200, when camera NDVI

7 for the deciduous region of interest is essentially stable at its maximum summertime value.

8 During this period, camera $\mathrm{NDVI}^{\mathrm{R}}$ at the 30 -minute time step ( $\left.1 \mathrm{SD}=0.13\right)$ was 10 times more

9 variable than at the daily time step $(1 \mathrm{SD}=0.01)$. Much of the variability in the 30 -minute data

10 results from imagery captured under low-to-intermediate light levels ( $1 \mathrm{SD}=0.17$ for PPFD <

$11500 \mu \mathrm{mol} \mathrm{m} \mathrm{s}^{-1} ; 1 \mathrm{SD}=0.06$ for PPFD $\left.\geq 500 \mu \mathrm{mol} \mathrm{m} \mathrm{s}^{-1}\right)$. At both dawn and dusk, camera

$12 \mathrm{NDVI}^{\mathrm{R}}$ is considerably lower, and markedly more variable, than at mid-day, indicating both a

13 systematic bias and a lower signal-to-noise ratio under low-light conditions. However, excluding

14 periods with PPFD $<200 \mu \mathrm{mol} \mathrm{m} \mathrm{m}^{-2} \mathrm{~s}^{-1}$, the diurnal pattern (data from 6 a.m. to 6 p.m.) in camera

$15 \mathrm{NDVI}^{\mathrm{R}}$ is negligible: a polynomial function of time of day accounts for no more than $2 \%$ of the

16 total variance in camera $\mathrm{NDVI}^{\mathrm{R}}$. This suggests that illumination geometry has only a minimal

17 effect on camera NDVI ${ }^{\mathrm{R}}$. Similarly, although camera $\mathrm{NDVI}^{\mathrm{R}}$ is highly variable when the ratio of

18 diffuse/total PPFD is $\geq 0.90$, the noisy observations are all associated with PPFD $<500 \mu \mathrm{mol} \mathrm{m}^{-2}$

$19 \mathrm{~s}^{-1}$.

20 A final - and important, because it can not be entirely eliminated by filtering for lower-

21 light conditions - source of variation in camera $\mathrm{NDVI}^{\mathrm{R}}$ is the ratio of the exposure times for the

$22 \mathrm{RGB}$ and RGB+NIR imagery, i.e. $E_{\text {ratio }}=E_{\mathrm{Y}} / E_{\mathrm{Z}}$. A second-order polynomial of $E_{\text {ratio }}$ explains

$2373 \%$ of the variation in 30 -minute camera $\mathrm{NDVI}^{\mathrm{R}}$, with both low $(<2)$ and high $(>5)$ values of

$24 E_{\text {ratio }}$ contributing to this pattern. Filtering for periods with PPFD $\geq 500 \mu \mathrm{mol} \mathrm{m} \mathrm{m}^{-2}$ eliminates

25 most instances of low $E_{\text {ratio. }}$. High values of $E_{\text {ratio }}$ are most often associated with anomalously long

26 RGB exposures (high $E_{\mathrm{Y}}$ ). The RGB images associated with these long exposures are

27 characterized by an anomalously bluish cast. We are unable to identify the specific lighting

28 conditions (total PPFD, PPFD variance, direct PPFD, diffuse PPFD, or the direct/total PPFD

29 ratio) that cause this effect. However, even considering only data acquired with $2<E_{\text {ratio }}<5$,

$30 E_{\text {ratio }}$ still accounts for $40 \%$ of the variation in camera $\mathrm{NDVI}^{\mathrm{R}}$ between day 160 and day 200.

31 Using a fixed exposure setting (with potentially different values of $E_{\mathrm{Y}}$ and $E_{\mathrm{Z}}$ ), and limiting the 
1 analysis to high-light, mid-day conditions, it should be possible to eliminate this source of

2 variability in camera $\mathrm{NDVI}^{\mathrm{R}}$.

$4 \quad$ Discussion

5 We have proposed a method by which an off-the-shelf networked digital camera,

6 originally marketed for security monitoring applications, can be repurposed and used to obtain

7 information about the spectral properties of vegetation in both visible and NIR wavelengths, and

8 thus to calculate NDVI-style indices (cf. Nijland et al. 2013, who found that imagery from a

9 filtered, infrared-sensitive camera was of no more value than conventional RGB imagery for

10 tracking plant phenology and health). The lab experiment described here is used as a proof-of-

11 concept (Figs. 2, 4), and shows that not only can we back out the IR component from the

12 RGB+NIR imagery, but also that our method for exposure-correction of auto-exposed imagery is

13 effective. The field data, on the other hand, show how this method can be applied for long term

14 monitoring of vegetation phenology in real-world conditions with varying solar illumination and

15 weather conditions. Specifically, we show good agreement between data obtained using the

16 camera NDVI method and the seasonal trajectory of NDVI measured using radiometric sensors

17 (Fig. 5). This approach is highly economical: the camera used here retails for about US\$1200,

18 which is a fraction of the cost of a pair (upward- and downward-looking) of multi-channel

19 radiometric sensors. While we did not rely on a reference panel for standardization, inclusion of

20 a grey Spectralon (or other diffuse reflector) panel within the field of view of the camera would

21 potentially be of value for normalization under changing illumination conditions (e.g. cloudy vs.

22 sunny days); however, the results shown here suggest that even without this kind of calibration

23 standard, it is possible to obtain high-quality data on the seasonal variation in canopy NDVI.

24 Although our field experiment was conducted in a mixed forest ecosystem, there is no reason to

25 believe that this method would not be applicable in other vegetation types, especially those with

26 a strong seasonal cycle such as crops or grasslands. The signal-to-noise ratio may, however, be

27 inadequate for tracking the seasonality of evergreen vegetation with a high LAI. This method is

28 currently implemented at more than 40 core sites within the PhenoCam network

29 (http://phenocam.sr.unh.edu), and future analysis of those data will confirm the viability of this

30 approach. 
Networked cameras are well suited to field monitoring applications because with Internet

2 connectivity (using cell phone modems, this is now possible even at remote field sites) images

3 can be archived to an off-site server, and camera functionality can be monitored remotely.

4 Furthermore, since this eliminates the need for manually swapping out memory cards, the

5 potential for shifts in camera alignment are minimized, making it is easier to maintain a constant

6 field of view. This facilitates image processing and improves data quality.

We acknowledge that cameras with red and NIR sensitivity, primarily designed for

8 precision agriculture applications, have been developed and are commercially available (e.g. the

9 Agricultural Digital Camera by Tetracam, Inc., Chatsworth, CA, which retails for US\$4800).

10 These have been used for ecological studies (e.g. Steltzer and Welker, 2006; Higgins et al.,

11 2011), but we are not aware of this type of camera being installed in the field for continuous,

12 long-term monitoring applications. Conventional digital cameras have also been customized and

13 used for similar work, but these have typically made use of two-camera systems, with one

14 camera filtered for visible wavelengths and the other for near infrared wavelengths (e.g.

15 Shibayama et al., 2009, 2011; Sakamoto et al., 2010, 2012; see also Nijland et al., 2013). What is

16 unique about the present approach is that by controlling the camera's infrared cut filter we

17 instead obtained sequential images from a single sensor, rather than simultaneous images from

18 two sensors. Not only does the single-camera approach reduce costs, it also eliminates issues

19 related to parallax, sensor calibration, and image alignment. Our method could, in principle, be

20 used with other camera systems although the linear scaling coefficients $(a, b)$ reported here are

21 probably specific to the StarDot NetCam SC IR.

22 Compared to other low-cost, sensor-based methods for monitoring seasonal changes in

23 the spectral properties of vegetation (e.g. radiometric instruments based on photodiodes, Garrity

24 et al., 2010, or light emitting diodes, Ryu et al., 2010), a clear advantage of the camera approach

25 is that it yields high-resolution images. This enables tracking the phenology of different

26 organisms or groups of organisms by breaking the image into different regions of interest - e.g.,

27 deciduous and coniferous trees (e.g. Fig. 5E,F). False-color images similar to those traditionally

28 generated from satellite imagery can also be generated using near infrared, red, and green bands

29 (i.e. XRG rather than RGB), as shown in Figure 6. Thus, the camera effectively becomes a four-

30 channel imaging sensor. We acknowledge that higher-quality spectral image data could,

31 potentially, be obtained from existing, commercially available multichannel or hyper-spectral 
1 cameras, e.g. Surface Optics SOC-710 or TetraCam MCA. However, for budget-limited

2 observational and experimental studies, the system proposed here may represent an acceptable

3 compromise, given its substantially lower cost and proven performance.

$4 \quad$ Our camera NDVI approach is conceptually similar to that used to obtain broadband

5 NDVI from readily available radiometric measurements of incident and canopy-reflected visible

6 (PPFD) and total shortwave radiation (Huemmrich et al., 1999; Wang et al., 2004; Jenkins et al.,

7 2007; see review in Richardson et al., 2013b). The similarity of camera NDVI to radiometer

8 NDVI, and the dissimilarity between camera NDVI and camera $g_{\mathrm{CC}}$, highlights the potential for

9 camera NDVI to provide different information about the state of the canopy than can be obtained

10 using only visible-wavelength (RGB) imagery. Furthermore, indices such as EVI (the enhanced

11 vegetation index, which also uses blue channel information) can be calculated from the camera

12 imagery in a similar manner. The resulting data should therefore be of great value for "apples-to-

13 apples" evaluation of landscape phenology products derived from satellite remote sensing, as

14 suitable data for this kind of analysis are currently lacking (cf. Hufkens et al., 2012; note that

15 landscape heterogeneity and the mismatch between the camera field of view and the satellite

16 pixel to which it is being compared remain outstanding challenges). More generally, camera

17 NDVI could be used for continuous monitoring of plant stress in greenhouse or nursery

18 applications, or even quantifying responses to experimental manipulations in large field

19 experiments (e.g. nutrient additions, elevated $\mathrm{CO}_{2}$, rainfall exclusion, etc.).

\section{Acknowledgments}

22 This work was supported by the National Science Foundation's Macrosystems Biology

23 program (award EF-1065029). We acknowledge additional support from the US National Park

24 Service Inventory and Monitoring Program and the USA National Phenology Network, through

25 a grant from the United States Geological Survey (award G10AP00129). Research at Harvard

26 Forest is partially supported by the National Science Foundation's LTER program (awards DEB-

27 0080592, DEB-1237491). The contents of this paper are solely the responsibility of the authors

28 and do not necessarily represent the official views of NSF or USGS.

\section{References}


Betancourt JL, Schwartz MD, Breshears DD, Cayan DR, Dettinger MD, Inouye DW, Post E, Reed BC. 2005. Implementing a U.S. National Phenology Network. Eos, Transactions American Geophysical Union 86: 539.

Garrity SR, Vierling LA, Bickford K. 2010. A simple filtered photodiode instrument for continuous measurement of narrowband NDVI and PRI over vegetated canopies. Agricultural and Forest Meteorology 150: 489-496.

Higgins SI, Delgado-Cartay MD, February EC, Combrink HJ. 2011. Is there a temporal niche separation in the leaf phenology of savanna trees and grasses? Journal of Biogeography 38: 2165-2175.

Huemmrich KF, Black TA, Jarvis PG, McCaughey JH, Hall FG. 1999. High temporal resolution NDVI phenology from micrometeorological radiation sensors. Journal of Geophysical Research-Atmospheres 104: 27935-27944.

Hufkens K, Friedl M, Sonnentag O, Braswell BH, Milliman T, Richardson AD. 2012. Linking near-surface and satellite remote sensing measurements of deciduous broadleaf forest phenology. Remote Sensing of Environment 117: 307-321.

Jenkins JP, Richardson AD, Braswell BH, Ollinger SV, Hollinger DY, Smith ML. 2007. Refining light-use efficiency calculations for a deciduous forest canopy using simultaneous tower-based carbon flux and radiometric measurements. Agricultural and Forest Meteorology 143: 64-79.

Keenan TF, Darby B, Felts E, Sonnentag O, Friedl M, Hufkens K, O'Keefe J, Klosterman S, Munger JW, Toomey M, Richardson AD. 2013. Tracking forest phenology and seasonal physiology using digital repeat photography: a critical assessment. Ecological Applications in review.

Migliavacca M, Sonnentag O, Keenan TF, Cescatti A, O'Keefe J, Richardson AD. 2012. On the uncertainty of phenological responses to climate change, and implications for a terrestrial biosphere model. Biogeosciences 9: 2063-2083.

Morisette JT, Richardson AD, Knapp AK, Fisher JI, Graham EA, Abatzoglou J, Wilson BE, Breshears DD, Henebry GM, Hanes JM, Liang L. 2009. Tracking the rhythm of the seasons in the face of global change: phenological research in the 21 st century. Frontiers in Ecology and the Environment 7: 253-260. 
Nijland W, de Jong R, de Jong SM, Wulder MA, Bater CW, Coops NC. 2013. Monitoring plant condition and phenology using infrared sensitive consumer grade digital cameras. Agricultural and Forest Meteorology 184: 98-106.

Polgar CA, Primack RB. 2011. Leaf-out phenology of temperate woody plants: from trees to ecosystems. New Phytologist 191: 926-941.

Richardson AD, Anderson RS, Arain MA, Barr AG, Bohrer G, Chen G, Chen JM, Ciais P, Davis KJ, Desai AR, Dietze MC, Dragoni D, Garrity SR, Gough CM, Grant R, Hollinger DY, Margolis HA, McCaughey H, Migliavacca M, Monson RK, Munger JW, Poulter B, Raczka BM, Ricciuto DM, Sahoo AK, Schaefer K, Tian H, Vargas R, Verbeeck H, Xiao J, Xue Y. 2012. Terrestrial biosphere models need better representation of vegetation phenology: results from the North American Carbon Program Site Synthesis. Global Change Biology 18: 566-584.

Richardson AD, Braswell BH, Hollinger DY, Jenkins JP, Ollinger SV. 2009. Near-surface remote sensing of spatial and temporal variation in canopy phenology. Ecological Applications 19: 1417-1428.

Richardson AD, Jenkins JP, Braswell BH, Hollinger DY, Ollinger SV, Smith ML. 2007. Use of digital webcam images to track spring green-up in a deciduous broadleaf forest. Oecologia 152: 323-334.

Richardson AD, Keenan TF, Migliavacca M, Ryu Y, Sonnentag O, Toomey M. 2013a. Climate change, phenology, and phenological control of vegetation feedbacks to the climate system. Agricultural and Forest Meteorology 169: 156-173.

Richardson AD, Klosterman S, Toomey M 2013b. Chapter 22: Near-surface sensor-derived phenology. In: Schwartz MD ed. Phenology: An Integrative Environmental Science (2nd Edition). New York: Springer, 413-430.

Rosenzweig C, Casassa G, Karoly DJ, Imeson A, Liu C, Menzel A, Rawlins S, Root TL, Seguin B, Tryjanowski P 2007. Assessment of observed changes and responses in natural and managed systems. In: Parry ML, Canziani OF, Palutikof JP, van der Linden PJ, Hanson CE eds. Climate Change 2007: Impacts, Adaptation and Vulnerability. Contribution of Working Group II to the Fourth Assessment Report of the Intergovernmental Panel on Climate Change. Cambridge, UK: Cambridge UP, 79-131. 
Ryu Y, Baldocchi DD, Verfaillie J, Ma S, Falk M, Ruiz-Mercado I, Hehn T, Sonnentag O. 2010. Testing the performance of a novel spectral reflectance sensor, built with light emitting diodes (LEDs), to monitor ecosystem metabolism, structure and function. Agricultural and Forest Meteorology 150: 1597-1606.

Sakamoto T, Gitelson AA, Nguy-Robertson AL, Arkebauer TJ, Wardlow BD, Suyker AE, Verma SB, Shibayama M. 2012. An alternative method using digital cameras for continuous monitoring of crop status. Agricultural and Forest Meteorology 154: 113-126.

Sakamoto T, Shibayama M, Takada E, Inoue A, Morita K, Takahashi W, Miura S, Kimura A. 2010. Detecting seasonal changes in crop community structure using day and night digital images. Photogrammetric Engineering and Remote Sensing 76: 713-726.

Shibayama M, Sakamoto T, Takada E, Inoue A, Morita K, Takahashi W, Kimura A. 2009. Continuous monitoring of visible and near-infrared band reflectance from a rice paddy for determining nitrogen uptake using digital cameras. Plant Production Science 12: 293306.

Shibayama M, Sakamoto T, Takada E, Inoue A, Morita K, Takahashi W, Kimura A. 2011. Estimating paddy rice leaf area index with fixed point continuous observation of near infrared reflectance using a calibrated digital camera. Plant Production Science 14: 3046.

Sonnentag O, Hufkens K, Teshera-Sterne C, Young AM, Friedl M, Braswell BH, Milliman T, O'Keefe J, Richardson AD. 2012. Digital repeat photography for phenological research in forest ecosystems. Agricultural and Forest Meteorology 152: 159-177.

Steltzer H, Welker JM. 2006. Modeling the effect of photosynthetic vegetation properties on the NDVI-LAI relationship. Ecology 87: 2765-2772.

Tucker CJ. 1979. Red and photographic infrared linear combinations for monitoring vegetation. Remote Sensing of Environment 8: 127-150.

Wang Q, Tenhunen J, Dinh NQ, Reichstein M, Vesala T, Keronen P. 2004. Similarities in ground- and satellite-based NDVI time series and their relationship to physiological activity of a Scots pine forest in Finland. Remote Sensing of Environment 93: 225-237.

White MA, de Beurs KM, Didan K, Inouye DW, Richardson AD, Jensen OP, O'Keefe J, Zhang G, Nemani RR, van Leeuwen WJD, Brown JF, de Wit A, Schaepman M, Lin X, Dettinger M, Bailey AS, Kimball J, Schwartz MD, Baldocchi DD, Lee JT, 
Lauenroth WK. 2009. Intercomparison, interpretation, and assessment of spring phenology in North America estimated from remote sensing for 1982-2006. Global Change Biology 15: 2335-2359.

4 Zhang X, Friedl MA, Schaaf CB. 2006. Global vegetation phenology from moderate resolution 5 imaging spectroradiometer (MODIS): Evaluation of global patterns and comparison with

6 in situ measurements. J. Geophysical Research-Biogeosciences 111: Art. No. G04017. 
1 Figure 1. Reflectance spectra of the 51 samples (thin grey lines) used in the laboratory 2 experiment. The heavier black lines indicate representative spectra from a healthy green leaf 3 (bottom), a yellowing leaf (middle), and a red (top) leaf.

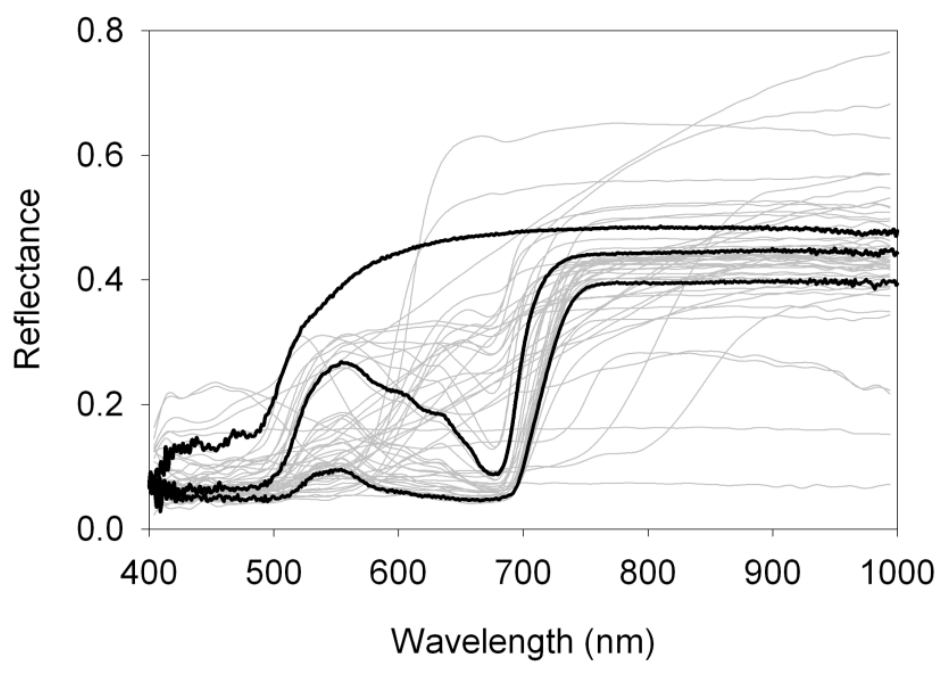

4 
1 Figure 2. Correlation of digital number (color bands extracted from fixed-exposure camera 2 imagery) and mean reflectance (measured with a spectroradiometer) for $n=51$ samples in 3 laboratory experiment. (a) mean reflectance from 570-660 nm vs. digital number of camera red 4 channel; (b) mean reflectance from 805-815 nm vs. digital number of NIR component of camera $5 \quad$ RGB+NIR imagery; (c) spectroradiometer NDVI vs. camera NDVI calculated using $R_{\mathrm{DN}}$ and $6 X_{\mathrm{DN}}$.
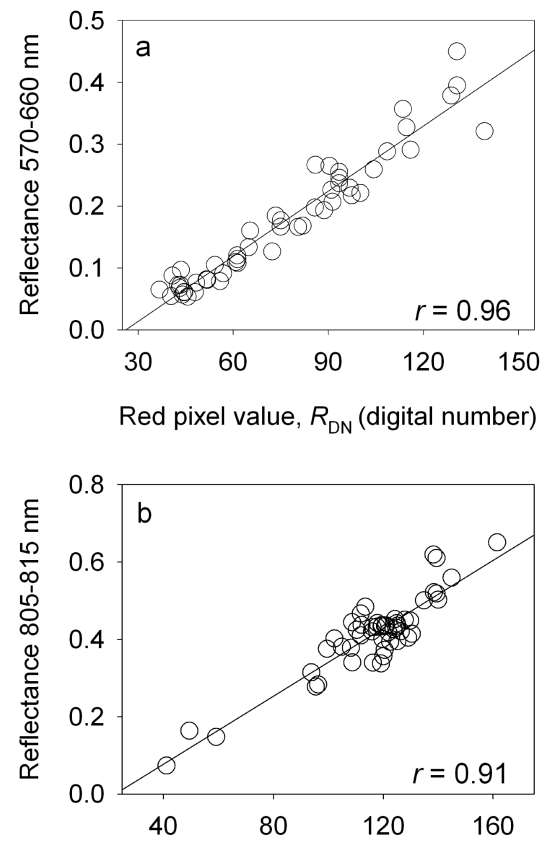

NIR pixel value, $X_{D N}$ (digital number)

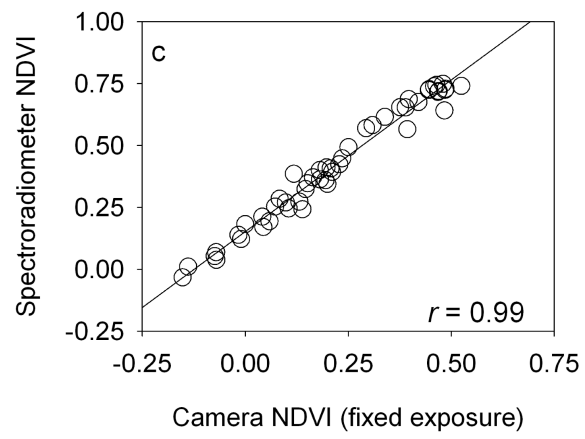


1 Figure 3. Contour plot showing linear correlation (Pearson's $r$ ) of pixel values (digital numbers) 2 of individual color bands, from digital camera imagery, with mean spectral reflectance over the 3 region from $\lambda_{1}$ ( $x$ axis) to $\lambda_{2}(y$ axis) $\mathrm{nm}$, as measured on a spectroradiometer. (a) Camera blue 4 channel; (b) camera green channel; (c) camera red channel; (d) NIR component of RGB+NIR 5 imagery.
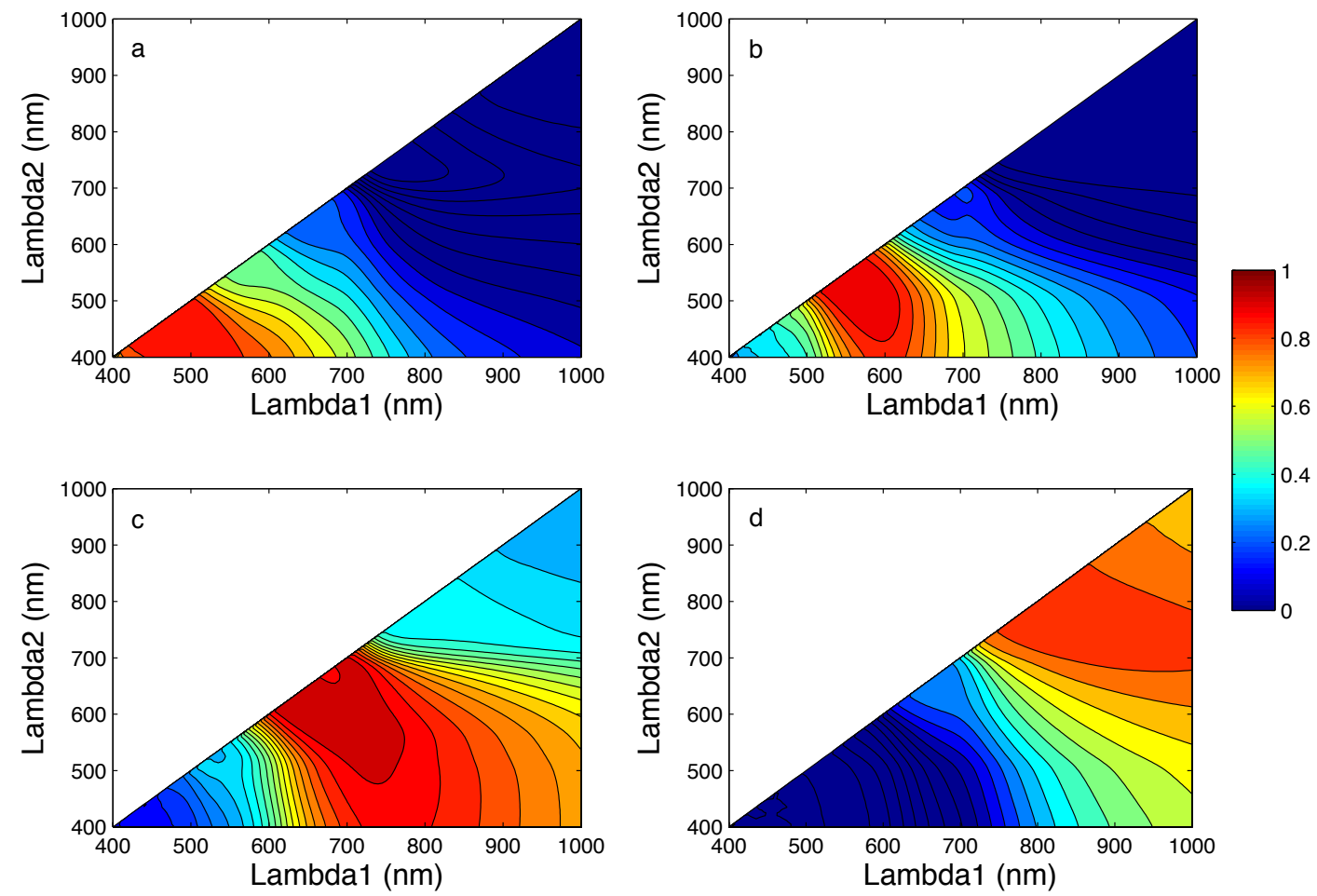
1 Figure 4. Correlation of exposure-adjusted digital number (color bands extracted from auto-

2 exposure camera imagery) and mean reflectance (measured with a spectroradiometer) for $n=51$

3 samples in laboratory experiment. (a) mean reflectance from $575-710 \mathrm{~nm}$ vs. exposure-adjusted

4 digital number of camera red channel $\left(R_{\mathrm{DN}}^{\prime},\right)$; (b) mean reflectance from $800-815 \mathrm{~nm}$ vs.

5 exposure-adjusted digital number of NIR component of camera RGB+NIR imagery $\left(X_{\mathrm{DN}}^{\prime},\right)$; (c)

6 spectroradiometer NDVI vs. camera NDVI calculated using $R_{\mathrm{DN}}^{\prime}$ and $X_{\mathrm{DN}}^{\prime}$ vs. spectroradiometer 7 NDVI.
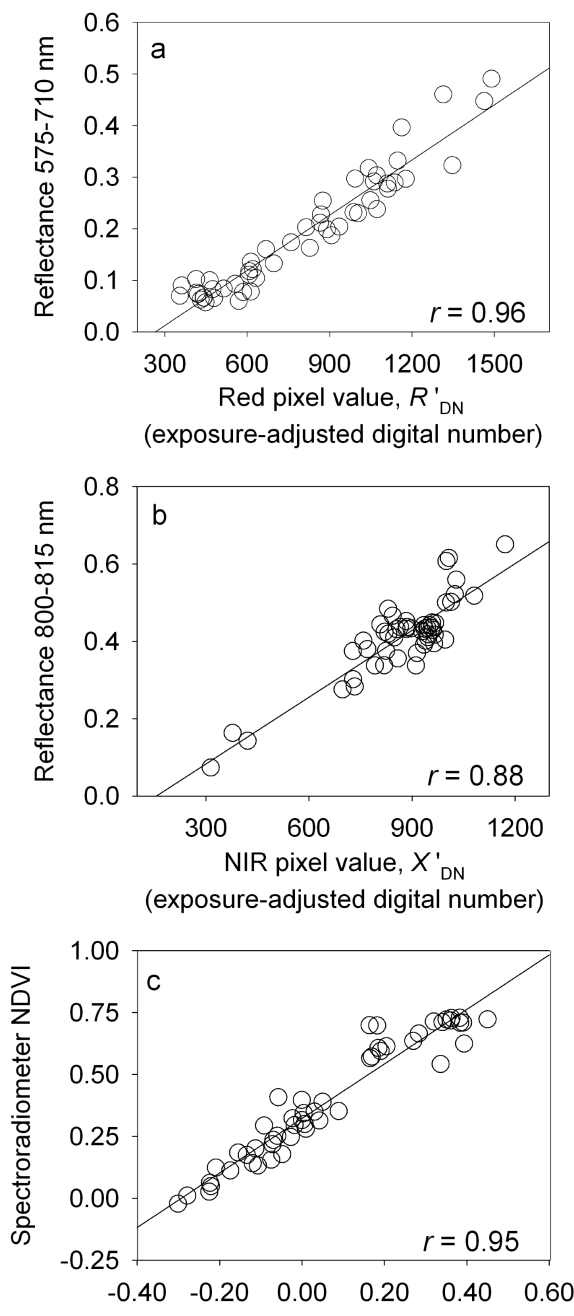

Camera NDVI (exposure-adjusted) 
1 Figure 5. Time series of daily means (calculated for PPFD $\geq 200 \mu \mathrm{mol} \mathrm{m}^{-2} \mathrm{~s}^{-1}$ ) of vegetation 2 indices calculated from radiometric instruments (a, d) and digital camera imagery, analyzed 3 separately for deciduous (b, e) and coniferous (c, f) regions of interest, from instruments 4 mounted on the Harvard Forest Barn Tower. In (d), the gray filled circles are the mean value of 5 MODIS NDVI from a $3 \times 3$ window centered on the tower pixel. $g_{\mathrm{CC}}$ is the green chromatic 6 coordinate, NDVI is the normalized difference vegetation index.
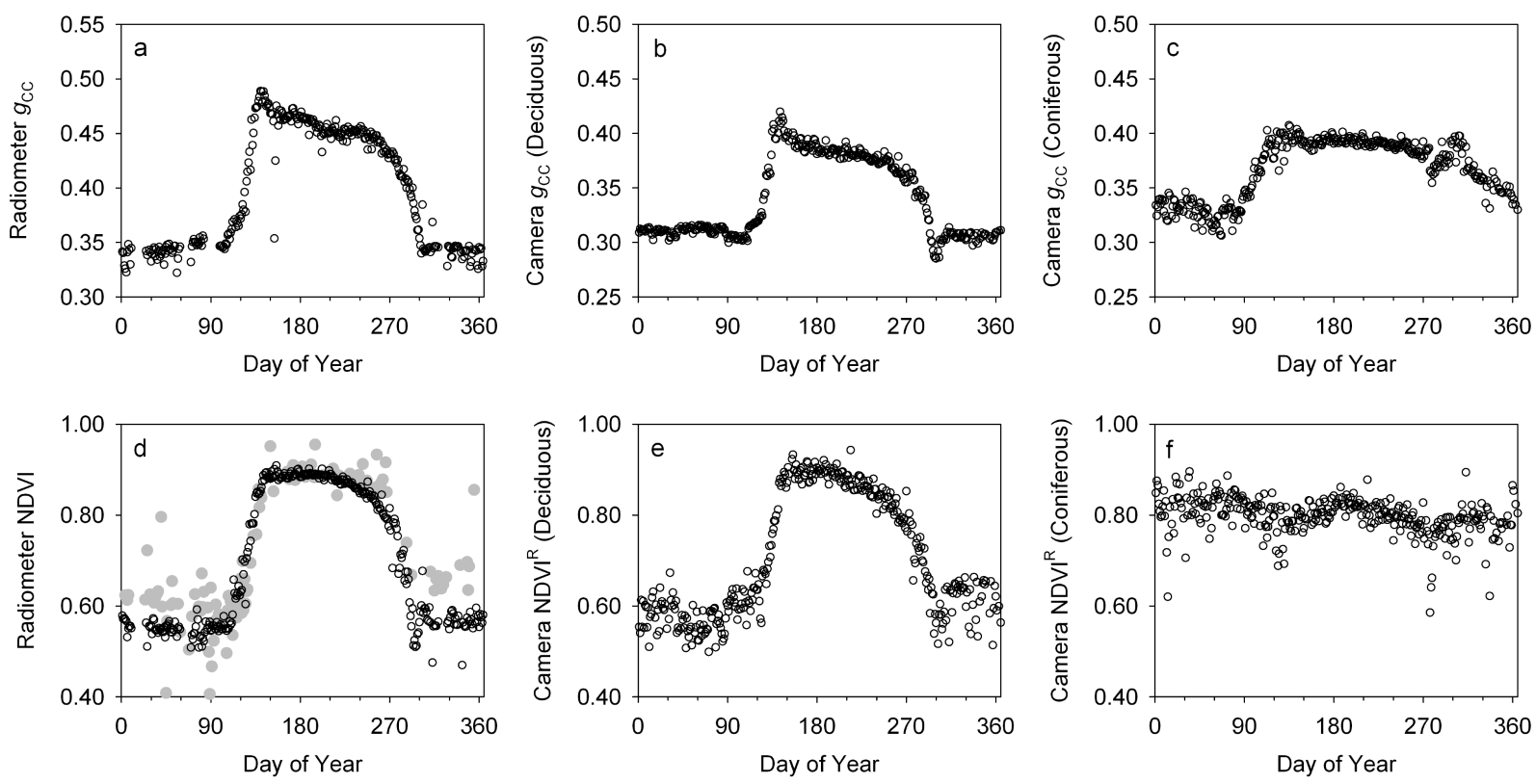
1 Figure 6. Winter (February 1, top) and summer (July 6, bottom) false-color images (XRG) 2 obtained from an infrared-enabled security camera mounted on the Harvard Forest Barn Tower. 3 The near infrared component $(\mathrm{X})$ is mapped to the red $(\mathrm{R})$ channel, the red channel is mapped to 4 the green $(\mathrm{G})$ channel, and the green channel is mapped to the blue channel. Both images were 5 taken from the top of the tower at 4 PM local standard time. The evergreen trees that are clearly 6 visible in the top image are white pine (Pinus strobus).
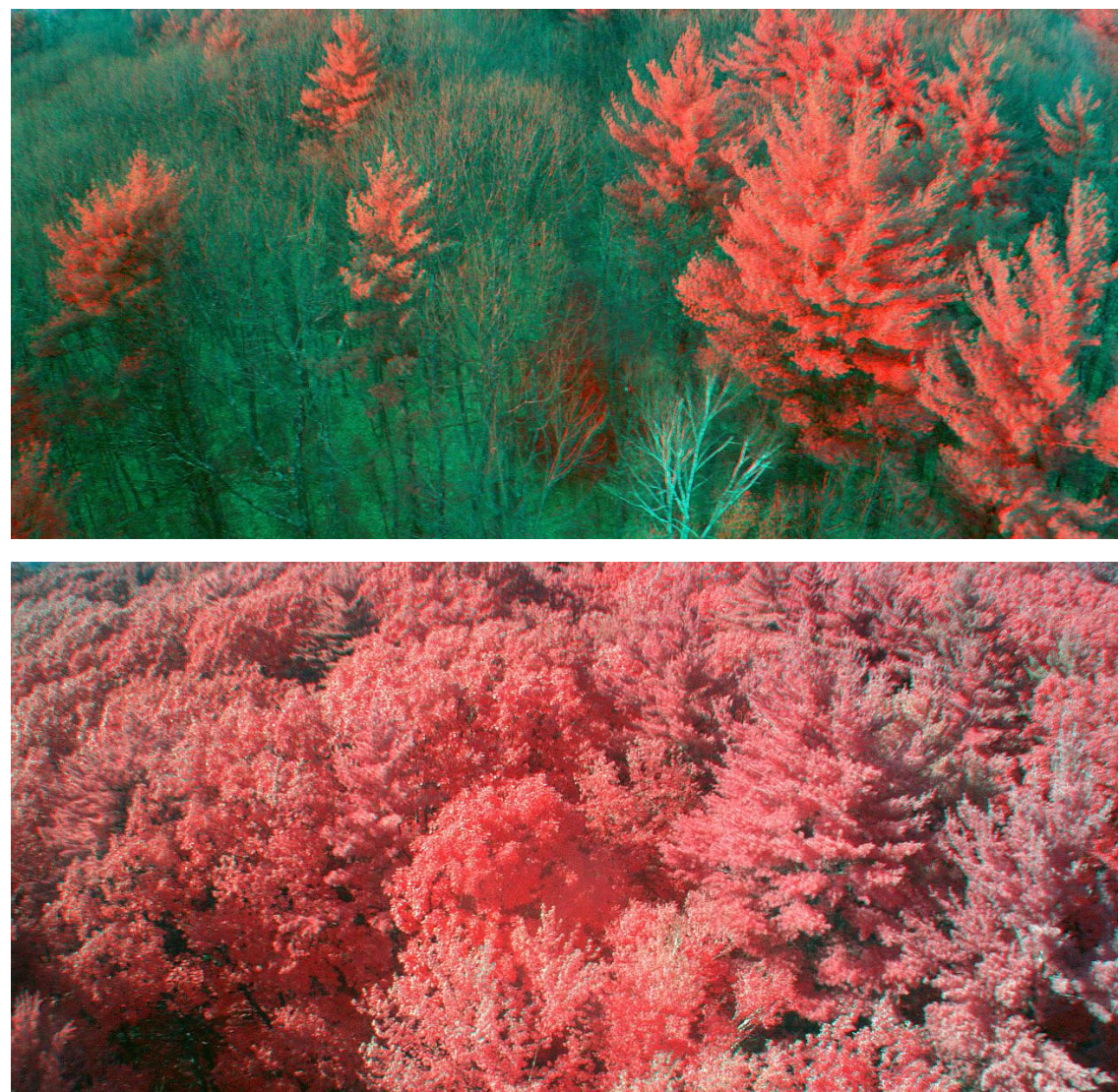